\title{
Levodopa-Carbidopa Intestinal Gel Infusion Therapy Discontinuation: A Ten-Year Retrospective Analysis of 204 Treated Patients
}

This article was published in the following Dove Press journal:

Neuropsychiatric Disease and Treatment

\author{
Viorelia Adelina Constantin, ,2,* \\ József Attila Szász, (iD) ${ }^{1,3, *}$ \\ Károly Orbán-Kis, ${ }^{1,4}$ \\ Elena Cecilia Rosca, (iD ${ }^{5,6}$ \\ Maria Popovici, ${ }^{7}$ Amalia Cornea, (iD) ${ }^{5,6}$ \\ Ligia Ariana Bancu, 8,9 \\ Marius Ciorba, (DD ${ }^{8,10}$ István Mihály, ${ }^{1,4}$ \\ Elöd Nagy, ${ }^{11,12}$ \\ Szabolcs Szatmári, (D) 1,3 \\ Mihaela Simu (D) 5,6 \\ '2nd Clinic of Neurology, Târgu Mureș County \\ Emergency Clinical Hospital, Târgu Mures, \\ Romania; 'Doctoral School, "Victor Babes" \\ University of Medicine and Pharmacy Timisoara, \\ Timisoara, Romania; ${ }^{3}$ Department of Neurology, \\ "George Emil Palade" University of Medicine, \\ Pharmacy, Science and Technology of Târgu Mures, \\ Târgu Mureș, Romania; ${ }^{4}$ Department of Physiology, \\ "George Emil Palade" University of Medicine, \\ Pharmacy, Science and Technology of Târgu Mureș, \\ Târgu Mureș, Romania; '5epartment of Neurology, \\ "Victor Babes" University of Medicine and Pharmacy \\ Timisoara, Timisoara, Romania; ${ }^{6}$ Department of \\ Neurology, "Pius Branzeu” Emergency Clinical \\ County Hospital, Timisoara, Romania; ${ }^{7}$ Neurotim \\ Med SRL, Timisoara, Romania; ${ }^{8}$ Department of \\ Internal Medicine, "George Emil Palade" University \\ of Medicine, Pharmacy, Science and Technology of \\ Târgu Mureș, Târgu Mureș, Romania; ${ }^{9} I^{\text {st }}$ Clinic of \\ Internal Medicine, Târgu Mureș County Emergency \\ Clinical Hospital, Târgu Mureș, Romania; \\ ${ }^{10}$ Department of Gastroenterology, Târgu Mureș \\ County Emergency Clinical Hospital, Târgu Mureș, \\ Romania; "Department of Biochemistry and \\ Environmental Chemistry, "George Emil Palade" \\ University of Medicine, Pharmacy, Science and \\ Technology of Târgu Mureș, Târgu Mureș, Romania; \\ ${ }^{12}$ Laboratory of Medical Analysis, Clinical County \\ Hospital Mureș, Târgu Mureș, Romania
}

*These authors contributed equally to this work

Correspondence: Károly Orbán-Kis Department of Physiology, "George Emil Palade" University of Medicine, Pharmacy, Science and Technology of Târgu Mureș, Gh. Marinescu Street No. 38, Târgu Mureș

540 I42, Romania

Tel +40743754525

Email karoly.orban-kis@umfst.ro
Background: Parkinson's disease (PD) is the second most common progressive neurodegenerative disease. In the advanced stages, the continuous delivery of levodopa (LD) as levodopa-carbidopa intestinal gel (LCIG) has demonstrated significant improvement of motor and nonmotor complications and improvement of the patients' quality of life (QoL). Despite the growing global experience with this treatment, anumber of unsolved practical issues remain, and currently, the data on the reasons that can lead to the discontinuation of LCIG are scarce.

Objective: In the present study, we aimed to analyze the causes that led to the discontinuation of LCIG therapy.

Methods: In this retrospective study, after 10 years of experience with LCIG as a therapeutic option in advanced PD, we analyzed the data of all dropout cases among the 204 patients that initiated LCIG therapy in two Romanian centers.

Results: Of the 204 patients enrolled, 43 patients dropped out. Disease duration until LCIG infusion was significantly longer $(11.67 \pm 4.98$ vs $9.44 \pm 3.44)$ and the overall clinical picture more sever (both regarding motor symptoms and cognitive decline) in dropout patients (compared to patients who continued treatment). The dropout patients also presented significant differences regarding the incidence of polyneuropathy $(32.5 \%$ vs $11.18 \%)$. The main cause of discontinuation was death.

Conclusion: The causes of discontinuation from LCIG therapy in Romanian patients are similar to those from other centers; however, the rate of dropouts is somewhat lower. The clinician's experience in selecting and treating the patients in advanced stages of PD can increase therapeutic adherence. Also, the presence of a well-trained caregiver along with the availability of a proper aftercare system is mandatory for maintaining the long-term benefits of the therapy and the overall best outcome possible. Targeted prospective studies are needed to confirm whether a more severe stage of the disease and cognitive impairment at the time of initiation, respectively, the association of polyneuropathy can be considered as predictive factors for dropout.

Keywords: advanced Parkinson's disease, levodopa-carbidopa intestinal gel, therapy discontinuation, polyneuropathy

\section{Introduction}

The second most common progressive neurodegenerative disease, Parkinson's disease (PD), remains a public health challenge. In the advanced stages of the disease (advanced Parkinson's disease, APD), patients develop potentially disabling severe motor complications: motor fluctuations and abnormal involuntary movements 
(dyskinesia, dystonia), which cannot be managed with optimized traditional oral/transdermal PD medications. ${ }^{1-3}$ The progressively worsening symptoms have a major impact on the patient's quality of life (QoL), ability to work, and self-reliance. This is the stage when invasive therapeutic options (device-aided therapies, DAT) are considered. The continuous delivery of levodopa (LD) as levodopa-carbidopa intestinal gel (LCIG) has demonstrated not only a significant improvement of motor complications but also improves the patients' ability to perform activities of daily living (ADL), treat their nonmotor symptoms, and improve QoL. ${ }^{4-6}$

Despite the growing global experience with this therapeutic option, a number of unresolved/unspecified practical issues remain, which represent numerous challenges even for movement disorders specialists with expertise in this area. Initiation and long-term maintenance of the efficacy of LCIG treatment require special attention and maximum involvement of a multidisciplinary team. Nonetheless, currently there are few articles available that analyze the reasons that led to the discontinuation of treatment on large groups of patients. ${ }^{7-10}$

The LCIG therapy became available in Romania in 2009. In 2016 a multicenter study was published analyzing data of the first 113 Romanian patients (9 university teaching hospital centers). ${ }^{11}$

\section{Objectives and Methods}

In recent publications, we evaluated the limits and specificity of the dopaminergic treatment before initiating LCIG therapy and we analyzed the spectrum of motor complications and profiles of patients with APD suitable for deviceaided therapies (DAT), all under the specific conditions in Romania. ${ }^{12-16}$ In this retrospective study, after 10 years of experience with LCIG as a therapeutic option in APD, we analyzed the causes that led to the discontinuation of the therapy. We analyzed the data of all dropout cases among the 204 patients with APD that initiated LCIG therapy before the end of 2018, in two Romanian centers with high patient turnover: Timisoara (TM, 90 patients) and Târgu Mureș (MS, 114 patients). Both centers are university teaching hospitals with important experience in LCIG therapy (the only DAT option available during the evaluated period) with an average of 9-10 LCIG initiations/ year. Also, both centers use the same protocols, ${ }^{17}$ have dedicated multidisciplinary teams (neurologist, gastroenterologist, psychiatrist, anesthesiologist, nurse with special expertise in PD and device-aided therapies), and benefits from the same aftercare system. Testing and initiation of therapy were done in each case under conditions of continuous hospitalization. The rigorous selection criteria and the preparation of the patients/relatives were already described in previous publications. ${ }^{12,13}$ All of the patients underwent a nasojejunal test to evaluate their response to continuous administration of LCIG and consequently were considered to be good responders. The data collection was approved by the local ethics committee of each center. Statistical analysis was conducted between patient groups using either one-way ANOVA, unpaired $t$-test, or Fisher's exact test. Values are presented as mean $\pm \mathrm{SD}$, unless otherwise specified.

\section{Results}

Of the 204 patients enrolled 43 patients dropped out. The general characteristics of the dropout patients are presented in Table 1.

We had discontinuation of treatment in 13 cases during the first year: 6 deceased patients (3 cardiac arrests, 2 strokes, and 1 pulmonary embolism case), 1 case of acute psychosis, 1 case of repeated tube displacement (previous gastric resection), 1 case of severe orthostatic hypotension and 4 cases of poor compliance and/or loss of family support (which we consider to be difficult to predict in some cases during the selection process, despite repeated, rigorous evaluations in hospital conditions). Although 18 patients had post-PEG complications and 17 patients had device-related complications, they were of low/medium severity and were not the reason for dropout. The average duration of LCIG treatment was 21.56 months (minimum of 0.5 , maximum of 60 months), but if we exclude the 4 cases of low compliance, the duration increases to 25.96 (minimum of 4 , maximum of 60 months). It must also be noted that LCIG treatment is generally used during the day (16-18 hours/day); nevertheless, in severe cases, the patient may need 24/24-hour treatment. This is reflected in a mean \pm SD LCIG administration time of $20.23 \pm 4.24$ in our study (see also Table 1 ).

The rate of polyneuropathy confirmed by neurophysiologic assessment was $32.5 \%$ (14/43) for dropout patients and $11.18 \%(18 / 161)$ for those who continued LCIG treatment. The latter includes only one case with acute, hyperalgesic symptoms, which improved after symptomatic treatment, and there was no need to stop LCIG treatment. In 15 cases, as we did not have updated electrophysiological data, we relied on a verbal questionnaire, which did not reveal subjective symptoms suggesting polyneuropathy. 
Table I General Characteristics of Patients Dropout from LCIG Treatment $(n=43)$

\begin{tabular}{|c|c|}
\hline Dropout Rate & $\begin{array}{l}21 \%(43 / 204 \\
\text { Patients) }\end{array}$ \\
\hline $\begin{array}{l}\text { Gender }(\mathrm{n}, \%) \\
\text { Male } \\
\text { Female }\end{array}$ & $\begin{array}{l}23(53.48 \%) \\
20(46.51 \%)\end{array}$ \\
\hline $\begin{array}{l}\text { Age (years, mean } \pm S D \text { ) } \\
\text { All patients } \\
\text { Male } \\
\text { Female }\end{array}$ & $\begin{array}{l}67.47 \pm 7.49 \\
67.13 \pm 8.02 \\
67.85 \pm 7.02\end{array}$ \\
\hline $\begin{array}{l}\text { Disease duration until LCIG infusion } \\
\text { Years, mean } \pm S D \\
\text { Years, median }\end{array}$ & $\begin{array}{l}\text { II. } 67 \pm 4.98 \\
\text { II }\end{array}$ \\
\hline $\begin{array}{l}\text { Levodopa until LCIG infusion } \\
\text { Frequency (x/day), mean } \pm \text { SD } \\
\text { Dose (mg/day), mean } \pm \text { SD }\end{array}$ & $\begin{array}{l}5.2 \pm 1.4 \\
894.2 \pm 290.4\end{array}$ \\
\hline $\begin{array}{l}\text { Other treatment until LCIG infusion, } n(\%) \\
\text { COMTi } \\
\text { DA } \\
\text { MAO-Bi } \\
\text { Amantadine }\end{array}$ & $\begin{array}{l}25(58.14 \%) \\
29(67.44 \%) \\
19(44.18 \%) \\
10(23.25 \%)\end{array}$ \\
\hline $\begin{array}{l}\text { MMSE score before initiation of LCIG infusion, } \\
\text { mean } \pm \text { SD } \\
\text { Theoretical (calculated) LCIG dose (mg/day), mean } \\
\pm S D \\
\text { Real (titrated/final) LCIG dose (mg/day), mean } \pm S D \\
\text { Titration days of LCIG infusion, mean } \pm S D\end{array}$ & $\begin{array}{l}24.88 \pm 2.37 \\
1026 \pm 274.1 \\
1399 \pm 433.3 \\
5.49 \pm 2.24\end{array}$ \\
\hline $\begin{array}{l}\text { LCIG administration } \\
\text { Duration (hours/day), mean } \pm \text { SD } \\
24 / 24 \text { hours, } n(\%)\end{array}$ & $\begin{array}{l}20.23 \pm 4.24 \\
23(53.49 \%)\end{array}$ \\
\hline $\begin{array}{l}\text { Duration of LCIG treatment (months), mean } \pm \text { SD } \\
\text { Patients that had PEG-J procedure-related AEs, } \\
\mathrm{n}(\%) \\
\text { Patients that had LCIG administration system- } \\
\text { related AEs, } \mathrm{n}(\%) \\
\text { Polyneuropathy, } \mathrm{n}(\%) \\
\text { Hallucinations/confusion related to LCIG, n (\%) }\end{array}$ & $\begin{array}{l}21.56 \pm 17.00 \\
18(41.8 \%) \\
17(39.5 \%) \\
14(32.5 \%) \\
3(6.9 \%)\end{array}$ \\
\hline
\end{tabular}

Abbreviations: $n$, number of patients; SD, standard deviation; LCIG, levodopacarbidopa intestinal gel; x/day, number of doses per day; COMTi, catecholO-methyltransferase inhibitor; DA, dopamine agonist; $\mathrm{MAO}-\mathrm{Bi}$, monoamine oxidase type B inhibitor; AEs, adverse events; PEG-J, percutaneous endoscopic gastrojejunostomy; MMSE, Mini-Mental State Examination.

The dropout patients presented significant differences regarding the clinical status before and after LCIG initiation, their clinical improvement confirming the efficiency of this treatment option (Table 2).

During the whole investigated period, 43 patients dropped out. Death occurred in 33 cases (the causes of deaths are presented in Figure 1). It is worth mentioning
Table 2 Clinical Evaluation of Dropout Patients Before and After LCIG Initiation

\begin{tabular}{|c|c|c|c|}
\hline & $\begin{array}{l}\text { Before } \\
\text { Testing } \\
\text { for } \\
\text { LCIG }\end{array}$ & $\begin{array}{l}\text { First full } \\
\text { Evaluation } \\
\text { After PEG-J }\end{array}$ & $\mathbf{P}$ \\
\hline Hoehn and Yahr score, mean $\pm S D$ & & & \\
\hline ON state & $3.5 I \pm 0.50$ & $3.14 \pm 0.35$ & 0.0004 \\
\hline OFF state & $4.58 \pm 0.50$ & $3.77 \pm 0.47$ & $<0.0001$ \\
\hline OFF duration (hours), mean $\pm \mathrm{SD}$ & $5.47 \pm 1.46$ & $1.79 \pm 0.7 \mid$ & 0.0001 \\
\hline Mild/moderate dyskinesia (n) & 27 & 25 & \\
\hline Duration (hours), mean $\pm S D$ & $2.48 \pm 0.80$ & $1.58 \pm 0.72$ & 0.0002 \\
\hline Severe dyskinesia (n) & 10 & 2 & \\
\hline Duration (hours), mean $\pm S D$ & $1.70 \pm 1.34$ & $1.50 \pm 0.7 \mid$ & NA \\
\hline Biphasic dyskinesia ( $n$ ) & 12 & 12 & \\
\hline Duration (hours), mean $\pm S D$ & $3.25 \pm 0.87$ & $1.50 \pm 0.43$ & 0.0001 \\
\hline
\end{tabular}

Notes: NA - statistical test cannot be performed, the number of patients is too low in second group $(n=2)$.

that we only had a single case in which we consider that the death may be related to the jejunal tube, a patient with intestinal-mesenteric infarction followed by sepsis. In the other 10 cases the cause of dropout was: psychosis in 2 cases, repeated tube displacement in 1 case, severe orthostatic hypotension in 1 case, recurrent colon carcinoma in 1 case, reduction of therapy efficiency in 1 case (after 24 months, caregiver option and decision), and poor compliance/loss of family support in 4 cases.

The comparative analysis between dropout patients and those who continued the treatment is presented in Table 3. Disease duration (years, mean $\pm \mathrm{SD}$ ) until LCIG was significantly longer in dropout patients $(11.67 \pm 4.98$ versus $9.44 \pm 3.44)$. Also, dropout patients had a more severe disease, both regarding motor symptoms and cognitive decline, when compared to patients who continued treatment.

\section{Discussion}

Despite the growing number of therapies with proven symptomatic efficacy in PD in the recent decades, substitution therapy with LD formulations (the gold standard in PD therapy) is key for the best clinical improvement at all stages of the disease. A major disadvantage of long-term LD treatment is the occurrence of motor complications (fluctuations and dyskinesias) that significantly impair the QoL; the rate of complications exceeds $90 \%$ after a 10-year disease duration. ${ }^{18}$ These disadvantages should be alleviated by 


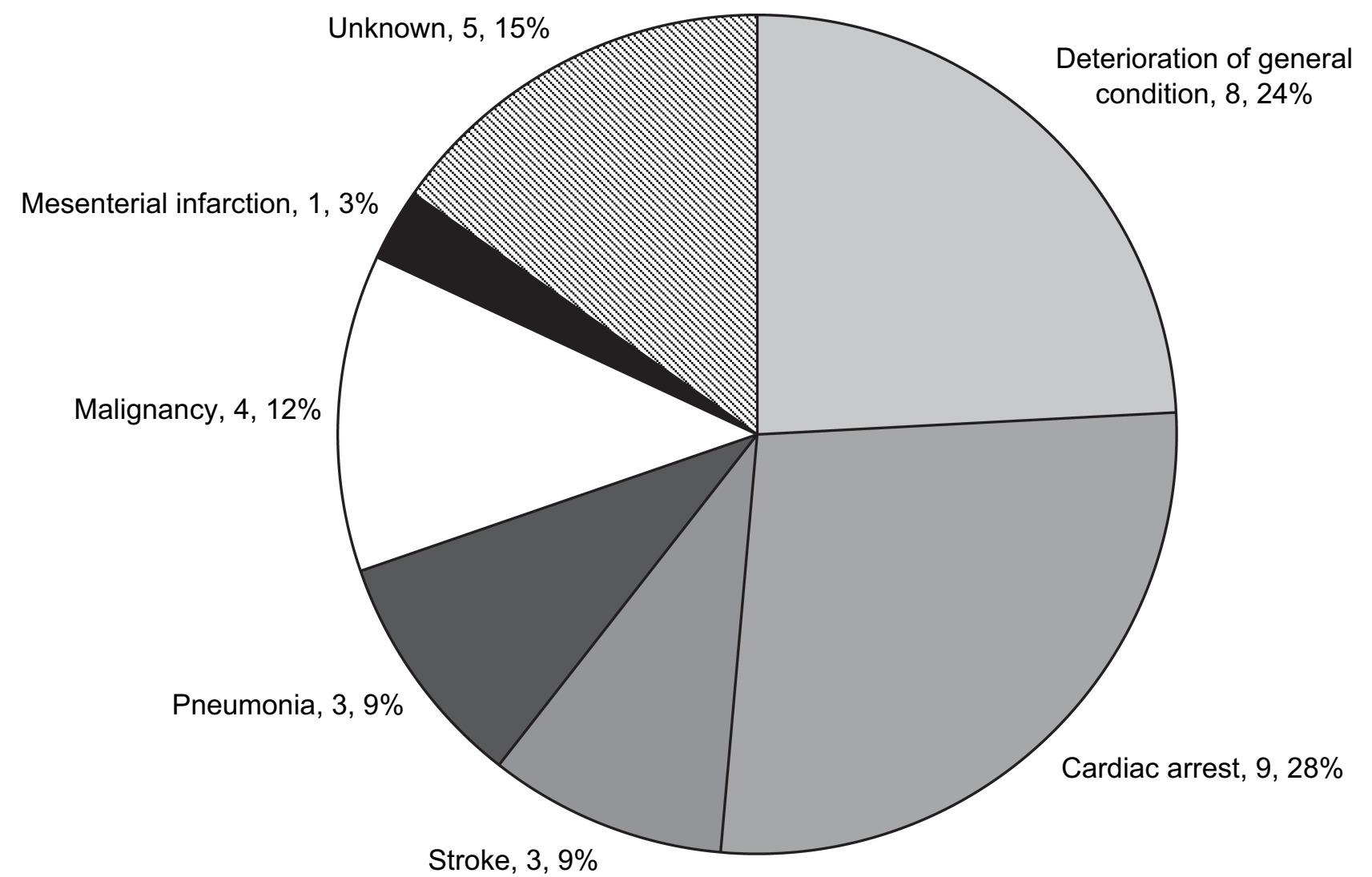

Figure I Cause of death in LCIG dropout patients $(n=33)$.

adding drugs that improve the LD bioavailability (in variable associations and dosages) such as the third-generation catechol-O-methyltransferase inhibitor (COMTi) opicapone, monoamine oxidase type $\mathrm{B}$ inhibitor (MAO-Bi) and glutamate modulator safinamide. ${ }^{19-21}$ Clinical studies evaluating the efficacy of inhaled LD showed its efficiency regarding the reduction of motor fluctuations that usually accompany standard preparations. ${ }^{22}$ The continuous delivery of LCIG directly into the proximal small intestine via percutaneous endoscopic gastro-jejunostomy (PEG-J) provides more stable plasma concentrations of LD. ${ }^{1,23,24}$ This reduces motor response fluctuations and has also been shown to improve non-motor complaints commonly associated with chronic oral LD therapy. The tolerability profile of LCIG is generally comparable with that of oral therapies, with the exception of events related to the delivery system and its placement. ${ }^{25}$ Furthermore, a recent systematic review and meta-analysis demonstrated that LCIG has comparable effects to STN-DBS on motor functions for advanced PD, with acceptable tolerability. ${ }^{26}$

Despite the unanimously recognized efficacy and experience gained in recent years, many (especially practical) issues related to the successful initiation of LCIG therapy as well as the maintenance of the efficacy in case of long-term therapy remain unclear. It should be noted that there is still no unanimously accepted definition of APD. ${ }^{1-3}$ In advanced stages of the disease, in addition to the inevitable motor complications, a wide range of non-motor symptoms/complications (NMS) worsen QoL and limit the therapeutic possibilities. As experts focused extensively in recent years on NMS in $\mathrm{PD}^{2,3,27-29}$ it has been documented that disability in the advanced stage of the disease is a blend of both LD-resistant motor symptoms and NMS. Patients therefore no longer fit into the "classic" definition of APD when characterized by disabling motor complications exclusively. Using a rigid set of eligibility criteria in the decision process to switch to DAT in general and LCIG in particular, is neither always helpful nor accurate. Furthermore, a consensus statement from an international panel of experts suggested that intrajejunal levodopa infusion is considered as both therapeutic and palliative in some countries for patients who have cognitive impairment or dementia, broadening its potential use beyond the strict motor improvement. This group also 
Table 3 Comparative Analysis of Dropout Patients and Those Who Continued Treatment

\begin{tabular}{|c|c|c|c|}
\hline & $\begin{array}{l}\text { Patients } \\
\text { Dropout } \\
\text { from LCIG } \\
\text { Treatment } \\
(n=43)\end{array}$ & $\begin{array}{l}\text { Continued } \\
\text { LCIG } \\
\text { Treatment } \\
(n=161)\end{array}$ & $\mathbf{p}$ \\
\hline $\begin{array}{l}\text { Gender, n (\%) } \\
\text { Male } \\
\text { Female }\end{array}$ & $\begin{array}{l}23(53.48) \\
20(46.5 I)\end{array}$ & $\begin{array}{l}99(6 I .49) \\
62(38.5 I)\end{array}$ & 0.3832 \\
\hline $\begin{array}{l}\text { Age (years), mean } \pm S D \\
\text { All patients } \\
\text { Male } \\
\text { Female }\end{array}$ & $\begin{array}{l}67.47 \pm 7.49 \\
67.13 \pm 8.02 \\
67.85 \pm 7.02\end{array}$ & $\begin{array}{l}64.04 \pm 7.42 \\
63.77 \pm 7.40 \\
64.47 \pm 7.49\end{array}$ & $\begin{array}{l}0.0739 \\
0.0651 \\
0.1248\end{array}$ \\
\hline $\begin{array}{l}\text { Disease duration until LCIG } \\
\text { infusion } \\
\text { Years, mean } \pm \text { SD } \\
\text { Years, median }\end{array}$ & $\begin{array}{l}11.67 \pm 4.98 \\
11\end{array}$ & $\begin{array}{l}9.44 \pm 3.44 \\
9\end{array}$ & 0.0174 \\
\hline $\begin{array}{l}\text { Hoehn and Yahr score, mean } \\
\pm \text { SD } \\
\text { ON state } \\
\text { OFF state } \\
\text { OFF duration (hours), mean } \\
\pm \text { SD }\end{array}$ & $\begin{array}{l}3.51 \pm 0.50 \\
4.58 \pm 0.50 \\
5.47 \pm 1.46\end{array}$ & $\begin{array}{l}3.13 \pm 0.39 \\
4.19 \pm 0.52 \\
4.60 \pm 0.97\end{array}$ & $\begin{array}{l}<0.0001 \\
<0.0001 \\
0.0002\end{array}$ \\
\hline $\begin{array}{l}\text { Levodopa until LCIG infusion } \\
\text { Frequency ( } x / \text { day), mean } \pm \text { SD } \\
\text { Dose (mg/day), mean } \pm S D \\
\text { MMSE score before } \\
\text { initiation of LCIG infusion, } \\
\text { mean } \pm \text { SD }\end{array}$ & $\begin{array}{l}5.2 \pm 1.4 \\
894.2 \pm 290.4 \\
24.88 \pm 2.37\end{array}$ & $\begin{array}{l}5.03 \pm 0.78 \\
918.0 \pm 249.1 \\
27.07 \pm 2.02\end{array}$ & $\begin{array}{l}0.8346 \\
0.6366 \\
<0.0001\end{array}$ \\
\hline $\begin{array}{l}\text { LCIG treatment duration } \\
\text { Months, mean } \pm \text { SD } \\
\text { Polyneuropathy, n (\%) } \\
\text { Hallucinations/confusion } \\
\text { related to LCIG, } \mathrm{n}(\%)\end{array}$ & $\begin{array}{l}21.56 \pm 17.00 \\
14(32.5) \\
3(6.9)\end{array}$ & $\begin{array}{l}30.14 \pm 22.52^{*} \\
18(11.18) \\
8(4.9)\end{array}$ & $\begin{array}{l}0.033 \\
0.0016 \\
0.7029\end{array}$ \\
\hline
\end{tabular}

Notes: *Calculated until 2019 , still ongoing.

suggested that LCIG may also be considered for patients older than 70 years who have mild or moderate cognitive impairment or severe depression. ${ }^{1}$ Further expert consensus is therefore required and needed.

Regarding the time of initiation, the LCIG titration (in the nasojejunal testing phase) and the management of the previous dopaminergic medication are largely "left" at the clinician's personal option and experience. The same is true regarding the maintenance or withdrawal of associated drugs for combination therapy. These facts explain the lack of clear recommendations from experts, although these would be particularly important for increasing longterm efficiency and lowering the dropout rate. It is rational to assume that polypharmacy and complex treatment regimens may contribute to non-adherence. These might have been the reasons why in many centers (even in clinical trials) the overnight switch was preferred from the last dopaminergic medication to LCIG (overlooking the risk of Dopamine Agonist Withdrawal Syndrome, DAWS). In this context, the results of the COSMOS study are expected with great interest (a multi-country, retrospective, cross-sectional, post-marketing observational study; the first study fully dedicated to collecting real-world data assessing add-on PD medication used before and during LCIG long-term therapy in a large patient cohort). ${ }^{30}$

In a previous publication, ${ }^{12}$ we discussed the permanent dilemma between the natural tendency (both from the APD patient's and the attending physician's perspective) to delay the moment of the initiation of an invasive therapy and the observation which is more and more outlined in the literature in the last years that the clinical benefits obtained with DAT are superior in patients with shorter disease duration. ${ }^{31}$ In other words, there is the possibility that in the case of "delayed" initiation, some of the benefits of an "on time" initiation may be lost. An "unjustified" delay may involve older patients with more comorbidities. Thus, in addition to losing an acceptable/improved QoL period, it requires more combined medication, with increased risk of drug interactions, side effects, and poor adherence.

Determining which APD patients may benefit from DAT can be challenging. Expert recommendations suggest that if the patient presents at least 2 hours off periods and/or 1 hour of severe dyskinesia, despite the administration of at least 5 doses of LD and with optimized oral/transdermal therapy, DAT should be taken into consideration. ${ }^{1,32,33}$ These characteristics were present in patients with APD (and potentially eligible for DAT) in the OBSERVE-PD study (crosssectional, observational study, conducted with 2615 PD patients at 128 movement disorder centers in 18 countries). ${ }^{34}$ However, in real-life practice, the duration and severity of the motor complications at the time of the decision for DAT may be even worse. In our previously presented study (311 APD patients), the patients that we considered not to have exhausted the limits of conservative treatment had on average $2.8 \pm 0.8$ hours off periods, whereas those considered suitable for DAT had $4.7 \pm 1.1$ hours off. ${ }^{12}$ Compared to these values, in this present study, patients who discontinued the LCIG treatment had a mean off period duration of 5.47 hours (Table 2). The fact that these patients were in a more advanced stage of the 
disease is also suggested by the high score on the Hoehn and Yahr (HY) scale: during on stage $3.51 \pm 0.50$, whereas during off stage $4.58 \pm 0.50$ (with 23 patients having a $\mathrm{HY}$ score of 5 during off stage). By comparison in our previous study the patients that were considered suitable for DAT had 3.34 \pm 0.5 HY score during on periods and $4.5 \pm 0.5 \mathrm{HY}$ score during off periods. ${ }^{12}$ In the GLORIA registry (24-month, multinational, non-interventional, observational registry; 375 APD patients received LCIG treatment at 75 movement disorder centers across 18 countries) the average HY value during on periods was $2.8 \pm 0.8$ whereas for the off period was $4.0 \pm 0.9 .^{5}$ The fact that the mean LCIG administration time was $20.23 \pm 4.24$ hours/24 hours (of which 23 cases required 24/24 administration) also suggests more severe PD.

Discontinuation rates published in literature are difficult to compare, given the different methods of data collection and the duration of the evaluated periods (both in pivotal and in open studies). In a retrospective review published by Nyholm et al, long-term data indicate that $31 \%$ of patients treated with LCIG discontinue therapy and $17 \%$ die by an 8 -year median treatment duration. ${ }^{10}$ In an Italian multicenter survey of 905 patients with long-term follow-up (mean center follow-up was 6.1 years \pm 3.0$)^{8}$ the $25.7 \%$ dropout rate was considered quite low compared to other series $^{35,36}$ where it reached nearly $40 \%$ and occurred most frequently during the first year of treatment. The causes that led to the dropout may change in time. Callandrella et al in a 2015 publication $^{37}$ identified two major causes of discontinuation during the first year: postsurgical stoma infection and worsening of dyskinesias. Compared to these data the $21 \%$ discontinuation rate in our group can be considered low. The mortality rate was similar to those found in literature, ${ }^{31}$ but there is a difference regarding the causes of dropouts during the first year. Out of the 13 patients 6 deceased, there were 4 cases of poor compliance and/or loss of family support, one case each of psychosis, repeated tube displacement and severe orthostatic hypotension. The death causes are very similar to those found in previous publications. ${ }^{38}$

In a recently published retrospective, longitudinal observational study, Artusi et al, investigating the potential predictors of mortality among numerous clinical and demographic features, observed that a lower MMSE score before starting LCIG negatively influenced survival. In particular, they found that an MMSE cut-off of 26 is significantly associated with mortality; patients scoring $<26$ have a 2.8 fold higher risk of death. ${ }^{38}$ In contrast to their results (MMSE score $26.3 \pm 3.3$ ), in our dropout group, the mean MMSE was $24.88 \pm 2.37$ (also significantly lower when compared to patients with ongoing treatment $27.07 \pm 2.02$ ).

Regarding polyneuropathy, in the last decade, it has become increasingly recognized that it occurs with higher frequency in PD patients on LD treatment compared with age-matched controls. ${ }^{39,40}$ A recent systematic review revealed that over one-third of $\mathrm{PD}$ patients in treatment with L-dopa may develop polyneuropathy, with a significantly higher prevalence of acute and subacute forms in those receiving LCIG. ${ }^{41}$ It has been hypothesized that a high-dose of LD favors high levels of homocysteine and methylmalonic acid or reduces the absorption of vitamins (B6, B12) and folate. Vitamin B6 and folate deficiency in the setting of LCIG infusion have been associated with weight loss and subacute axonal sensorimotor polyneuropathy. In the GLORIA registry polyneuropathy was found in $16(4.5 \%)$ cases. $^{5}$ In the Barcelona registry (72 APD patients with a mean observation time of 22 months and a maximum of 48 months) the authors reported two patients with polyneuropathy (no cause for dropout). ${ }^{36}$ Mancini et al evaluated 3 groups of consecutive PD patients: 50 on LCIG, 50 on oral LD, and 50 on other dopaminergic therapy. The frequency of polyneuropathy (with no other cause) was $28 \%$ in LCIGtreated, $20 \%$ in oral levodopa-treated, and $6 \%$ in other dopaminergic-treated PD patients. ${ }^{42}$ Slevin et al in an open-label extension of the double-blind pivotal study in APD patients treated with LCIG, over the entire study, reported polyneuropathy as an adverse event (AE) in 6 $(9.7 \%)$ patients; in none was this serious or led to study discontinuation. ${ }^{39}$ In the previously mentioned Italian multicenter survey chronic polyneuropathy was found in $10.6 \%$ of cases. ${ }^{8}$ In our dropout patients, we found a rate of polyneuropathy (confirmed by neurophysiologic assessment) of $32.5 \%$, which we consider high, even if in 3 cases a pre-existing condition might have contributed to this complication ( 2 cases of diabetes and 1 case of previous gastro-duodenal resection). Nevertheless, we do not consider the appearance of polyneuropathies as a direct cause of discontinuation.

In a recent study, we evaluated the characteristics of real-life therapeutic strategies versus therapeutic availability in PD patients and we mentioned the lack of add-on options and limited access to DAT in our region, which significantly influences the decision-making process. ${ }^{12}$ Based on those results and the findings of this study, 
despite all its limitations, we consider that a more severe stage of the disease and the presence of cognitive impairment can be considered as predictive factors for dropout. The association of polyneuropathy may have similar importance. We continue to believe that the careful evaluation and selection of patients, the existence of an adequately trained and involved caregiver as well as the initiation of LCIG treatment after prior testing in hospital conditions are essential elements for reaching the maximum therapeutic benefit and long-term efficacy. It is likely that the timeline change of dropout causes (especially in the first year) mentioned above is due to these factors. All APD patients tested and initiated with LCIG would improve regardless of their baseline characteristics. However, the long-term benefits of the treatment might be greater in patients with less advanced PD (both from the point of view of disease duration/severity of motor symptoms and complications). ${ }^{31}$ Recently there have been published opinions that the initiation of therapy can be done with the help of telemedicine, under outpatient titration or even without the NJ testing phase. ${ }^{43-45}$ Due to the potential of overlooking factors that would increase the dropout rate, our suggestion is that these options should be used only in cases where access to a tertiary center and implicitly the possibility of regular check-ups or the resolution of complications in an emergency regime is limited/ difficult (eg, large distances, already institutionalized patients, limitation of hospitalizations due to unforeseen circumstances, such as pandemics, etc.).

In our recent in-press article in which we evaluated the spectrum of gastrointestinal symptoms, we underlined the importance of defining the gastroenterological profile of patients with APD (which would also have the advantage of easing the decision in selecting the DAT option considered most appropriate, in other words identifying the category of patients with the greatest long-term benefits from LCIG treatment ${ }^{46}$. Therefore, taking all these aspects into account when initiating patients on LCIG, it would be useful to identify a "risk profile" of dropout (which is supposed to increase over time). Thus, in patients with multiple comorbidities, in those with cognitive impairment, in those who require significantly higher doses compared to the calculated doses and/or continuous administration for 24 hours, in those with dopaminergic side-effects, etc., additional measures such as more frequent evaluations, greater involvement of the aftercare surveillance could extend the therapeutic benefit of LCIG. In this context, we emphasize the importance of the ongoing multidisciplinary management (psychiatry, gastroenterology, etc.) even after initiating LCIG treatment.

We consider our results representative. In previous publications, we documented that the therapeutic strategies used in the treatment of $\mathrm{PD}$ in our region are similar to those found in literature. ${ }^{47-49}$ We want to reaffirm that in Romania the suitability of DAT for APD can only be assessed in a university teaching hospital setting. We also want to highlight the fact that in Romania a number of well-established LD preparations and adjunctive therapies (safinamide, opicapone, tolcapone, extended-release amantadine, or subcutaneous apomorphine injection for rapid relief of off episodes) that are well suited to the treatment of APD are still not available. Also, in our region the only available DAT is LCIG. $^{12}$ Therefore, we believe that all these factors, when considered together, faithfully reflect not only the Romanian but maybe the Central-Eastern European situation of challenges, limitations, and difficulties in the long-term management of LCIG treatment in APD. The retrospective method also has its limitations: the difficulty of assessing the impact of the involvement of the caregiver and incomplete or missing data for some characteristics. For instance, we could not document properly the weight loss, the exact cause of death of institutionalized patients and we may underestimate the total number of AEs and other relevant complications related to the LCIG administration system.

\section{Conclusion}

The causes of discontinuation from LCIG therapy in Romanian patients are similar to those from other centers; however, the rate of dropouts is somewhat lower.

The decade long acquired experience in selecting and treating the patients in advanced stages of PD can increase their therapeutic adherence. Moreover, the presence of a well-trained and involved caregiver along with the availability of a proper aftercare system is mandatory for maintaining the long-term benefits of the therapy and the overall best outcome possible.

Targeted prospective studies are needed to confirm whether a more severe stage of the disease and cognitive impairment at the time of initiation, respectively, the association of polyneuropathy can be considered as predictive factors for dropout. Also, a proper definition of the profile of the patient with APD which would maximally benefit for long time from LCIG treatment would be both useful and necessary. 


\section{Ethics}

This study enrolled patients admitted to the Neurological Clinics in Târgu Mureş and Timişoara, after they were informed about the study. According to national legislation all patients had to sign the written consent form of the teaching hospital. Furthermore, the study was approved by the Ethics Committee of the University of Medicine and Pharmacy from Târgu Mureș, approval no. 94/19.05.2017 (https://www.umfst. ro/universitate/comisii-de-etica/comisia-de-etica-a-cerce tarii-stiintifice/avize/2017.html), which requires all human studies to be conducted entirely in accordance with the Declaration of Helsinki.

\section{Author Contributions}

All authors made a significant contribution to the work reported, whether that is in the conception, study design, execution, acquisition of data, analysis and interpretation, or in all these areas; took part in drafting, revising or critically reviewing the article; gave final approval of the version to be published; have agreed on the journal to which the article has been submitted; and agree to be accountable for all aspects of the work. Szabolcs Szatmári and Mihaela Simu are joint last authors of this paper.

\section{Disclosure}

Viorelia Adelina Constantin reports personal fees from Abbvie, Bayer, UCB Pharma, and Worwag Pharma, outside the submitted work. József Attila Szász reports personal fees from Abbvie, Boehringer Ingelheim, Lundbeck, Novartis, Pfizer, Teva, and UCB, outside the submitted work. Maria Popovici reports speaking honoraria/travel grants from Abbvie, Bayer, Merck, and UCB. Nonfinancial support from Abbvie, and Merck, outside the submitted work. Amalia Cornea reports personal fees, non-financial support from Abbvie SRL, outside the submitted work. Ligia Ariana Bancu reports speaking honoraria from Abbvie, Alfasigma, Sanofi. Marius Ciorba reports non-financial support and speaking honoraria Abbvie, Alfasigma, Krka, Naturpharma, SunWave, Terapia SA, during the conduct of the study. Mihaela Simu reports personal fees from Abbvie, AOP ORP, Boehringer Ingelheim, Krka, Merck, Sanofi, Servier Pharma, Teva, UCB Pharma, outside the submitted work. Non-financial support from Abbvie, Merck, Sanofi, and Teva, outside the submitted work. The authors report no other conflicts of interest in this work.

\section{References}

1. Odin P, Ray Chaudhuri K, Slevin JT, et al. Collective physician perspectives on non-oral medication approaches for the management of clinically relevant unresolved issues in Parkinson's disease: consensus from an international survey and discussion program. Park Relat Disord. 2015;21(10):1133-1144. doi:10.1016/j.parkreldis.2015. 07.020

2. Titova N, Martinez-Martin P, Katunina E, Chaudhuri KR. Advanced Parkinson's or "complex phase" Parkinson's disease? Re-evaluation is needed. J Neural Transm. 2017;124(12):1529-1537. doi:10.1007/ s00702-017-1799-3

3. Krüger R, Hilker R, Winkler C, et al. Advanced stages of PD: interventional therapies and related patient-centered care. $J$ Neural Transm. 2016;123(1):31-43. doi:10.1007/s00702-015-1418-0

4. Olanow CW, Kieburtz K, Odin P, et al. Continuous intrajejunal infusion of levodopa-carbidopa intestinal gel for patients with advanced Parkinson's disease: a randomised, controlled, doubleblind, double-dummy study. Lancet Neurol. 2014;13(2):141-149. doi:10.1016/S1474-4422(13)70293-X

5. Antonini A, Poewe W, Chaudhuri KR, et al. Levodopa-carbidopa intestinal gel in advanced Parkinson's: final results of the GLORIA registry. Park Relat Disord. 2017;45:13-20. doi:10.1016/j. parkreldis.2017.09.018

6. Juhász A, Aschermann Z, Ács P, et al. Levodopa/carbidopa intestinal gel can improve both motor and non-motor experiences of daily living in Parkinson's disease: an open-label study. Parkinsonism Relat Disord. 2017;37:79-86. doi:10.1016/j.parkreldis.2017.02.001

7. Udd M, Lyytinen J, Eerola-Rautio J, et al. Problems related to levodopa-carbidopa intestinal gel treatment in advanced Parkinson's disease. Brain Behav. 2017;7(7):1-7. doi:10.1002/brb3.737

8. Sensi M, Cossu G, Mancini F, et al. Which patients discontinue? Issues on Levodopa/carbidopa intestinal gel treatment: italian multicentre survey of 905 patients with long-term follow-up. Park Relat Disord. 2017;38(February):90-92. doi:10.1016/j.parkreldis.2017.02.020

9. Wang L, Li J, Chen J. Levodopa-carbidopa intestinal gel in Parkinson's disease: a systematic review and meta-analysis. Front Neurol. 2018;9(July). doi:10.3389/fneur.2018.00620

10. Nyholm D, Klangemo K, Johansson A. Levodopa/carbidopa intestinal gel infusion long-term therapy in advanced Parkinson's disease. Eur J Neurol. 2012;19(8):1079-1085. doi:10.1111/j.1468-1331.2012.03679.x

11. Băjenaru O, Ene A, Popescu BO, et al. The effect of levodopacarbidopa intestinal gel infusion long-term therapy on motor complications in advanced Parkinson's disease: a multicenter Romanian experience. J Neural Transm. 2016;123(4):407-414. doi:10.1007/ s00702-015-1496-z

12. Szász JA, Constantin VA, Orbán-Kis K, et al. Profile of patients with advanced Parkinson's disease suitable for device-aided therapies: retrospective data of a large cohort of romanian patients. Neuropsychiatr Dis Treat. 2019;15:3187-3195. doi:10.2147/ndt. s230052

13. Szász JA, Szatmári S, Constantin V, et al. Characteristics of levodopa treatment in advanced Parkinson's disease in the experiences of the neurology clinics of Târgu Mures, Romania $[\mathrm{Az}$ orális levodopakezelés jellegzetességei előrehaladott Parkinson-kórban a marosvásárhelyi neurológiai klinikák tap]. Orv Hetil. 2019;160 (17):662-669. doi:10.1556/650.2019.31354

14. Szász J, Constantin V, Orbán-Kis K, et al. Characteristics of dopaminergic treatments in advanced Parkinson's before levodopa-carbidopa intestinal gel infusion: data from 107 tested patients. Mov Disord. 2018;33:171.

15. Szasz J, Constantin V, Orban-Kis K, et al. Spectrum of motor complications in advanced Parkinson's disease: data from a large Romanian case series evaluated for suitability for device aided therapy. Mov Disord. 2019;34(2):210. doi:10.1002/mds.27795 
16. Szász JA, Constantin V, Orbán-Kis K, et al. Dopamine agonists in advanced Parkinson's disease: data from a large cohort of Romanian patients. J Parkinsons Dis. 2019;9(1):128. doi:10.3233/JPD-199900

17. Worlich Pedersen S, Clausen J, Gregerslund MM. Practical guidance on how to handle levodopa/carbidopa intestinal gel therapy of advanced PD in a movement disorder clinic. Open Neurol J. 2012;6 (1):37-50. doi:10.2174/1874205x01206010037

18. Ahlskog JE, Muenter MD. Frequency of levodopa-related dyskinesias and motor fluctuations as estimated from the cumulative literature. Mov Disord. 2001;16(3):448-458. doi:10.1002/mds.1090

19. Fabbri M, Ferreira JJ, Lees A, et al. Opicapone for the treatment of Parkinson's disease: a review of a new licensed medicine. Mov Disord. 2018;33(10):1528-1539. doi:10.1002/mds.27475

20. Borgohain R, Szasz J, Stanzione P, et al. Randomized trial of safinamide add-on to levodopa in Parkinson's disease with motor fluctuations. Mov Disord. 2014;29(2):229-237. doi:10.1002/mds.25751

21. Borgohain R, Szasz J, Stanzione P, et al. Two-year, randomized, controlled study of safinamide as add-on to levodopa in mid to late Parkinson's disease. Mov Disord. 2014;29(10):1273-1280. doi:10.1002/mds. 25961

22. Patel AB, Jimenez-Shahed J. Profile of inhaled levodopa and its potential in the treatment of Parkinson's disease: evidence to date. Neuropsychiatr Dis Treat. 2018;14:2955-2964. doi:10.2147/NDT. S147633

23. Nyholm D, Odin P, Johansson A, et al. Pharmacokinetics of levodopa, carbidopa, and 3-O-methyldopa following 16-hour jejunal infusion of levodopa-carbidopa intestinal gel in advanced Parkinson's disease patients. AAPS J. 2013;15(2):316-323. doi:10.1208/s12248012-9439-1

24. Othman AA, Dutta S. Population pharmacokinetics of levodopa in subjects with advanced Parkinson's disease: levodopa-carbidopa intestinal gel infusion vs. oral tablets. $\mathrm{Br} J$ Clin Pharmacol. 2014;78(1):94-105. doi:10.1111/bcp.12324

25. Müller T, Laar TV, Cornblath DR, et al. Peripheral neuropathy in Parkinson's disease: levodopa exposure and implications for duodenal delivery. Park Relat Disord. 2013;19(5):501-507. doi:10.1016/j. parkreldis.2013.02.006

26. Liu XD, Bao Y, Liu GJ. Comparison between levodopa-carbidopa intestinal gel infusion and subthalamic nucleus deep-brain stimulation for advanced Parkinson's disease: a systematic review and metaanalysis. Front Neurol. 2019;10(AUG):1-10. doi:10.3389/fneur.2019. 00934

27. Hermanowicz N, Jones SA, Hauser RA. Impact of non-motor symptoms in Parkinson's disease: a PMDAlliance survey. Neuropsychiatr Dis Treat. 2019;15:2205-2212. doi:10.2147/ndt.s213917

28. Szatmari S, Illigens BMW, Siepmann T, Pinter A, Takats A, Bereczki D. Neuropsychiatric symptoms in untreated Parkinson's disease. Neuropsychiatr Dis Treat. 2017;13:815-826. doi:10.2147/ NDT.S130997

29. Romosan A-M, Romosan R-S, Bredicean AC, Simu MA, Bredicean AC, Simu MA. Affective theory of mind in Parkinson's disease: the effect of cognitive performance. Neuropsychiatr Dis Treat. 2019;15:2521-2535. doi:10.2147/NDT.S219288

30. Fasano A, Parra JC, Gurevich T, et al. Utilization of monotherapy and combination therapies in advanced Parkinson's disease patients during levodopa-carbidopa intestinal gel treatment from the cosmos study. J Neurol Sci. 2019;405:212-213. doi:10.1016/j.jns.2019. 10.1195

31. Regidor I, Santos-Garciá D, Catalán MJ, et al. Impact of disease duration in effectiveness of treatment with levodopa-carbidopa intestinal gel and factors leading to discontinuation. J Parkinsons Dis. 2019;9(1):173-182. doi:10.3233/JPD-181324

32. Luquin MR, Kulisevsky J, Martinez-Martin P, Mir P, Tolosa ES. Consensus on the definition of advanced Parkinson's disease: a neurologists-based delphi study (CEPA Study). Parkinsons Dis. 2017;2017:1-8. doi:10.1155/2017/4047392
33. Antonini A, Stoessl AJ, Kleinman LS, et al. Developing consensus among movement disorder specialists on clinical indicators for identification and management of advanced Parkinson's disease: a multicountry Delphi-panel approach. Curr Med Res Opin. 2018;34 (12):2063-2073. doi:10.1080/03007995.2018.1502165

34. Fasano A, Fung VSC, Lopiano L, et al. Characterizing advanced Parkinson's disease: OBSERVE-PD observational study results of 2615 patients. BMC Neurol. 2019;19(1):1-11. doi:10.1186/s12883019-1276-8

35. Lang AE, Rodriguez RL, Boyd JT, et al. Integrated safety of levodopa-carbidopa intestinal gel from prospective clinical trials. Mov Disord. 2016;31(4):538-546. doi:10.1002/mds.26485

36. Buongiorno M, Antonelli F, Cámara A, et al. Long-term response to continuous duodenal infusion of levodopa/carbidopa gel in patients with advanced Parkinson disease: the Barcelona registry. Park Relat Disord. 2015;21(8):871-876. doi:10.1016/j.parkreldis.2015.05.014

37. Calandrella D, Romito LM, Elia AE, et al. Causes of withdrawal of duodenal levodopa infusion in advanced Parkinson disease. Neurology. 2015;84(16):1669-1672. doi:10.1212/WNL.0000000000001500

38. Artusi CA, Balestrino R, Imbalzano G, et al. Beyond 10 years of levodopa intestinal infusion experience: analysis of mortality and its predictors. Park Relat Disord. 2019;(October):0-1. doi:10.1016/j. parkreldis.2019.10.004

39. Slevin JT, Fernandez HH, Zadikoff C, et al. Long-term safety and maintenance of efficacy of levodopa-carbidopa intestinal gel: an open-label extension of the double-blind pivotal study in advanced Parkinson's disease patients. J Parkinsons Dis. 2015;5(1):165-174. doi:10.3233/JPD-140456

40. Rajabally YA, Martey J. Neuropathy in Parkinson disease Prevalence and determinants. Neurology. 2011;77(22):1947-1950. doi:10.1212/ WNL.0b013e31823a0ee4

41. Romagnolo A, Merola A, Artusi CA, Rizzone MG, Zibetti M, Lopiano L. Levodopa-induced neuropathy: a systematic review. Mov Disord Clin Pract. 2019;6(2):96-103. doi:10.1002/mdc3.12688

42. Mancini F, Comi C, Oggioni GD, et al. Prevalence and features of peripheral neuropathy in Parkinson's disease patients under different therapeutic regimens. Park Relat Disord. 2014;20(1):27-31. doi:10.1016/j.parkreldis.2013.09.007

43. Willows T, Dizdar N, Nyholm D, et al. Initiation of levodopacarbidopa intestinal gel infusion using telemedicine (video communication system) facilitates efficient and well-accepted home titration in patients with advanced Parkinson's disease. J Parkinsons Dis. 2017;7(4):719-728. doi:10.3233/JPD-161048

44. Amjad F, Bhatti D, Davis TL, et al. Current Practices for Outpatient Initiation of Levodopa-Carbidopa Intestinal Gel for Management of Advanced Parkinson's Disease in the United States. Adv Ther. 2019;36(9):2233-2246. doi:10.1007/s12325-019-01014-4

45. Vijiaratnam N, Hewer S, Varley S, et al. Levodopa-carbidopa intestinal gel: is the naso-jejunal phase a redundant convention? Intern Med J. 2018;48(4):469-471. doi:10.1111/imj.13754

46. Szasz JA, Szatmari S, Constantin V, et al. The importance of evaluation of gastrointestinal features in advanced Parkinson's disease. Orv Hetil. 2020:161. doi:10.1556/650.2020.31782.

47. Szász JA, Orbán-Kis K, Constantin VA, et al. Therapeutic strategies in the early stages of Parkinson's disease: a cross-sectional evaluation of 15 years' experience with a large cohort of Romanian patients. Neuropsychiatr Dis Treat. 2019;15:831-838. doi:10.2147/NDT.S197630

48. Szász J, Constantin V, Fazakas P, et al. The role of selective monoamine oxidase B inhibitors in the therapeutic strategy of Parkinson's disease in the neurology clinics of Tirgu Mures County Emergency Clinical Hospital. Orv Hetil. 2017;158(51):2023-2028. doi:10.1556/ 650.2017.30914

49. Szász JA, Constantin V, Mihály I, et al. Dopamine agonists in Parkinson's disease therapy - 15 years of experience of the neurological clinics from Tirgu Mures. A cross-sectional study. Ideggyogy Sz. 2019;72(5-6):187-193. doi:10.18071/isz.72.0187 


\section{Publish your work in this journal}

Neuropsychiatric Disease and Treatment is an international, peerreviewed journal of clinical therapeutics and pharmacology focusing on concise rapid reporting of clinical or pre-clinical studies on a range of neuropsychiatric and neurological disorders. This journal is indexed on PubMed Central, the 'PsycINFO' database and CAS, and is the official journal of The International Neuropsychiatric Association (INA). The manuscript management system is completely online and includes a very quick and fair peer-review system, which is all easy to use. Visit http://www.dovepress.com/testimonials.php to read real quotes from published authors.

Submit your manuscript here: https://www.dovepress.com/neuropsychiatric-disease-and-treatment-journal 